Fixed Point Theory, 22(2021), No. 2, 727-738

DOI: $10.24193 /$ fpt-ro.2021.2.47

http://www.math.ubbcluj.ro/ nodeacj/sfptcj.html

\title{
EXISTENCE AND APPROXIMATION OF FIXED POINTS OF $\lambda$-HYBRID MAPPINGS IN COMPLETE CAT(0) SPACES
}

\author{
MAHMOOD KHOSHHAL* AND DAVOOD EBRAHIMI BAGHA** \\ *Department of Mathematics, Islamic Azad University, Khalkhal Branch, Khalkhal, Iran \\ E-mail: khoshhal_aukh@yahoo.com \\ ** Department of Mathematics, Islamic Azad University, \\ Central Tehran Branch, Tehran, Iran \\ E-mail: e_bagha@yahoo.com
}

\begin{abstract}
In this paper, we first state and establish some general existence theorems in Hadamard spaces. Then, we introduce class of $\lambda$-hybrid mappings in Hadamard spaces and prove existence of fixed point for such mappings. Finally, we establish convergence theorem of Mann's iterative process for $\lambda$-hybrid mappings.

Key Words and Phrases: Existence theorem, $\lambda$-hybrid mappings, nonexpansive mapping, fixed point, $\operatorname{CAT}(0)$ metric space.
\end{abstract}

2020 Mathematics Subject Classification: 47H09, 47H10, 47J25.

Acknowledgements. The authors would like to thank the anonymous referee for his/her precise consideration and valuable comments.

\section{REFERENCES}

[1] S. Alizadeha, H. Dehghan, F. Moradlou, $\Delta$-convergence theorems for inverse-strongly monotone mappings in CAT(0) spaces, Fixed Point Theory, 19(2018), no. 1, 45-56.

[2] K. Aoyama, S. Iemoto, F. Kohsaka, W. Takahashi, Fixed point and ergodic theorems for $\lambda$-hybrid mappings in Hilbert spaces, J. Nonlinear Convex Anal., 11(2010), 335-343.

[3] M. Bacak, Convex Analysis and Optimization in Hadamard Spaces, De Gruyter, Berlin, 2014.

[4] W. Ballmann, Lectures on Spaces of Nonpositive Curvature, in: DMV Seminar Band, vol. 25, Birkhäuser, Basel, 1995.

[5] I.D. Berg, I.G. Nikolaev, Quasilinearization and curvature of Alexandrov spaces, Geom. Dedicata, 133(2008), 195-218.

[6] E. Blum, W. Oettli, From optimization and variational inequalities to equilibrium problems, Math. Student, 63(1994), 123-145.

[7] M. Bridson, A. Haefliger, Metric Spaces of Nonpositive Curvature, Springer-Verlag, Berlin, Heidelberg, New York, 1999.

[8] H. Dehghan, J. Rooin, A characterization of metric projection in CAT(0) spaces, arXiv:1311.4174v1, 2013.

[9] S. Dhompongsa, W.A. Kirk, B. Panyanak, Nonexpansive set-valued mappings in metric and Banach spaces, J. Nonlinear and Convex Anal., 8(2007), 35-45.

[10] S. Dhompongsa, W.A. Kirk, B. Sims, Fixed points of uniformly lipschitzian mappings, Nonlinear Anal., 65(2006), 762-772. 
[11] S. Dhompongsa, B. Panyanak, On $\Delta$-convergence theorems in CAT(0) spaces, Comput. Math. Appl., 56(2008), 2572-2579.

[12] A. Gharajelo, H. Dehghan, Convergence theorems for strict pseudo-contractions in CAT(0) metric spaces, Filomat, 31(2017), 1967-1971.

[13] B.A. Kakavandi, Weak topologies in complete CAT(0) metric spaces, Proc. Amer. Math. Soc., 0002-9939 (2012), 11743-5.

[14] W.A. Kirk, Some recent results in metric fixed point theory, J. Fixed Point Theory Appl., 2(2007), 195-207.

[15] W.A. Kirk, B. Panyanak, A concept of convergence in geodesic spaces, Nonlinear Anal., 68(2008), 3689-3696.

[16] F. Kohsaka, W. Takahashi, Fixed point theorems for a class of nonlinear mappings related to maximal monotone operators in Banach spaces, Arch. Math., Basel, 91(2008), 166-177.

[17] T.C. Lim, Remarks on some fixed point theorems, Proc. Amer. Math. Soc., 60(1976), 179-182.

[18] A. Papadopoulos, Metric Spaces, Convexity and Nonpositive Curvature, IRMA Lectures in Mathematics and Theoretical Physics, 6. European Mathematical Society (EMS), Zürich, 2005.

[19] A. Pazy, Asymptotic behavior of contractions in Hilbert space, Israel J. Math., 9(1971), 230-240.

[20] S. Ranjbar, H. Khatibzadeh, Strong and $\Delta$-convergence to a zero of a monotone operator in CAT(0) spaces, Mediterr. J. Math., (2017), 14:56.

[21] H.L. Royden, Real Analysis, Macmillan, 1963.

[22] W. Takahashi, Existence theorems generalizing fixed point theorems for multivalued mappings, In: M.A. Thera, J.B. Baillon (Eds.), Fixed Point Theory and Applications, Pitman Research Notes in Mathematics Series, 252, Wiley, New York, 1991, 397-406.

[23] W. Takahashi, Fixed point theorems for new nonlinear mappings in a Hilbert space, J. Nonlinear Convex Anal., 11(2010), 79-88.

[24] W. Takahashi, Nonlinear Functional Analysis, Yokohoma Publishers, Yokohoma, 2000.

[25] W. Takahashi, J.C. Yao, Fixed point theorems and ergodic theorems for nonlinear mappings in a Hilbert space, Taiwanese J. Math., 15(2011), 457-472.

[26] R. Wangkeeree, P, Preechasilp, $\Delta$-convergence for generalized hybrid mappings in CAT(0)spaces, Bull. Malays. Math. Sci. Soc., 38(2015), 1127-1141.

Received: March 28, 2019; Accepted: May 16, 2020. 